\title{
Continuum Modeling and Analysis of Polymeric Sheet Reinforcement Subjected to Axial Pull
}

\author{
P. V. S. N. Pavan Kumar • Madhira R. Madhav • \\ M. Kumar
}

Received: 25 December 2014/ Accepted: 6 February 2015/Published online: 18 February 2015

(C) Springer International Publishing AG 2015

\begin{abstract}
Stability of reinforced soil structures depends on the soil-reinforcement interaction. Continuum modeling of polymeric sheet reinforcement-backfill interaction when subjected to axial pull at one end of the reinforcement is presented. Analysis is carried out by FLAC, soil is modeled as linear elastic material and reinforcement as cable elements. Displacements of reinforcement are quantified for different pullout forces. Variations of displacement and tension along the reinforcement length are presented. Effect of axial stiffness of reinforcement, soil-reinforcement interface shear stiffness and length of reinforcement are quantified. For a given pullout load the displacement of reinforcement decreases with increase of interface shear stiffness, axial stiffness of reinforcement and length of reinforcement. Results of the present numerical model compare closely with other mechanical models and pullout tests.
\end{abstract}

Keywords FLAC - Axial force - Reinforcement-backfill interaction $\cdot$ Axial stiffness $\cdot$ Interface shear stiffness

P. V. S. N. Pavan Kumar (

Department of Civil Engineering, Guru Nanak Institutions Technical Campus, Ibrahimpatnam 501506, Telangana, India e-mail: pavankumar.pvsn@gmail.com

\section{R. Madhav}

Department of Civil Engineering, Jawaharlal Nehru

Technological University, Hyderabad 500072, Telangana, India

e-mail: madhavmr@gmail.com

\section{Kumar}

Department of Civil Engineering, Osmania University,

Hyderabad 500007, Telangana, India

e-mail: kumartrans@gmail.com

\section{Introduction}

Reinforcement-soil interaction plays a key role in the design and analysis of reinforced soil structures such as walls, slopes, embankments and footings. Pullout resistance is quantified by laboratory and field pullout tests, mechanical and continuum analyses. A wide range of pullout tests are carried out based on different boundary conditions of the test apparatus on extensible reinforcement such as geogrids, geotextiles and inextensible reinforcement such as welded rods, steel strips, etc., for different types of backfill, granular soils with different particle sizes, shear strength, and unit weight. Pullout tests are conducted as displacement or load controlled tests [1-7]. Aiban and Ali [8] evaluated the interface friction characteristics of nonwoven geotextile for two different types of backfill. Khedkar and Mandal [9] conducted pullout tests on cellular reinforcement and results compared with the predictions based on finite element method. Suksiripattanapong et al. [10, 11] demonstrated the use of bearing reinforcement in reinforced earth wall and studied their pullout response. Lajevardi et al. [12, 13] conducted pullout tests on steel welded mesh reinforcement and results compared with the predictions based on analytical method mentioned in the French standard, NF P 94-270.

Pullout test data is widely used to estimate the soil-reinforcement bond capacity for designs based on limit equilibrium analyses [14]. For reinforcements with planar surfaces, the mechanism of interaction in pullout tests is controlled by the friction mobilized between soil and reinforcement. Abramento and Whittle [15, 16] conducted pullout tests on inextensible and extensible reinforcements. Hayashi et al. [17] conducted laboratory pullout tests and measured the elongation at several points along the geosynthetic reinforcement. Pradhan et al. [18] investigated 
the effect of normal pressure during pullout tests on a saturated clay-geosynthetic system.

Abramento and Whittle, Sobhi and Wu, and Long et al. $[15,19,20]$ proposed mechanical models based on respectively shear-lag analysis, rigid-plastic and non-uniform shear stress distribution at the soil-reinforcement interface to predict the pullout capacity of planar polymeric reinforcement. Weerasekara and Wijewickreme [21] developed a new analytical model to predict the pullout response of geotextiles combining the nonlinear responses of the geotextile and soil-geotextile interface characteristics.

Pullout interaction mechanisms between soil and geogrid reinforcements are more complex than those between soil and strip or sheet reinforcement. Pullout resistance of geogrids includes two components, viz., the interface shear resistance that takes place along the longitudinal ribs and to a lesser extent along the transverse ribs and the passive resistance that develops against the front of transverse ribs (Koerner et al. [22]). Passive pullout resistance that develops against transverse ribs was determined by general shear failure mechanism by Peterson and Anderson [23], punching failure mechanism by Jewell et al. [24] and a modified punching failure mechanism by Chai [25]. General shear and punching shear failure mechanisms have been reported to provide upper and lower bounds of experimental pullout test results by Palmeira and Milligan [2] and Jewell [14]. Large scale pullout tests and individual rib pullout tests were conducted on individual longitudinal and transverse ribs to quantify the contributions of passive and interface shear mechanisms to the overall pullout resistance of geogrids [26].

Sugimoto and Alagiyawanna [27] conducted finite element analysis to model the pullout behaviour of geogrid and demonstrated that the interface properties play a significant role in the FEM simulations of geogrid pullout behavior. Alam and Lo [28] studied pullout of steel grid soil reinforcement using FLAC 2D. Alam et al. [29] investigated the pullout behavior of steel grid reinforcement embedded in silty sand and compared the results with numerical analysis.

Madhav et al. [30] presented a mechanical model to demonstrate the pullout response of geosynthetic reinforcement. Applied pullout force mobilizes soil reinforcement interface shear stress along the reinforcement quantified by the bilinear shear stress displacement response. Elongation of reinforcement was considered and the resulting finite difference equation was solved by Gauss-Siedel iteration method. Gurung and Iwao [31] compared satisfactorily the results of theoretical pullout tests and experimental results. Gurung [32] presented one dimensional expression for pull-out of planar reinforcement that analyses small to large strain cases of inextensible to extensible reinforcements.
Problem Definition and Analysis

A typical sheet reinforcement of length, $L$ embedded at a depth, $D$, below ground level is subjected to an axial pullout force, $T_{\max }$, at node B (Fig. 1). Problem is modeled in FLAC 2D an explicit finite difference program with left and right boundaries of the model fixed in $x$-direction and bottom boundary fixed in both $x$ and $y$ directions (Figs. 1, $2)$. Grid of size $120 \times 120,90 \times 90,60 \times 60$ and $30 \times 30$ are considered in the analysis. Among them a grid of size $60 \times 60$ is found to give reliable results not affected by the boundary conditions and at an optimum time (Fig. 2). To reduce the iteration time and ensure stress equilibrium inside the elements the aspect ratio of grid is maintained as one throughout the analysis.

Soil is represented as a linear elastic material of unit weight, $\gamma=20 \mathrm{kN} / \mathrm{m}^{3}$, deformation modulus, $E_{\mathrm{s}}=30 \mathrm{MPa}$ and Poisson's ratio, $v=0.3$. These parameters are kept constant in the analysis. Four different forms of structural elements such as beam, cable, pile and support elements are available in the program. Planar sheet reinforcement is modeled by axial cable element with interface properties between the reinforcement and soil described by bonding of in situ reinforcement such as soil nails. Mobilized shear stress is limited based on the adhesion and the interface friction along the soil-sheet interface. Maximum interface shear stress from Fig. 3a is given by:

$\tau_{\max }=\frac{F_{\mathrm{s}}^{\max }}{L}=s_{\text {bond }}+\sigma_{\mathrm{c}}^{\prime} \times \tan \varphi_{\mathrm{r}} \times$ perimeter,

where $F_{\mathrm{s}}^{\mathrm{max}}$ is maximum shear force, $s_{\text {bond }}$ is the adhesion, $\sigma_{\mathrm{c}}^{\prime}$ is the effective normal stress acting on the

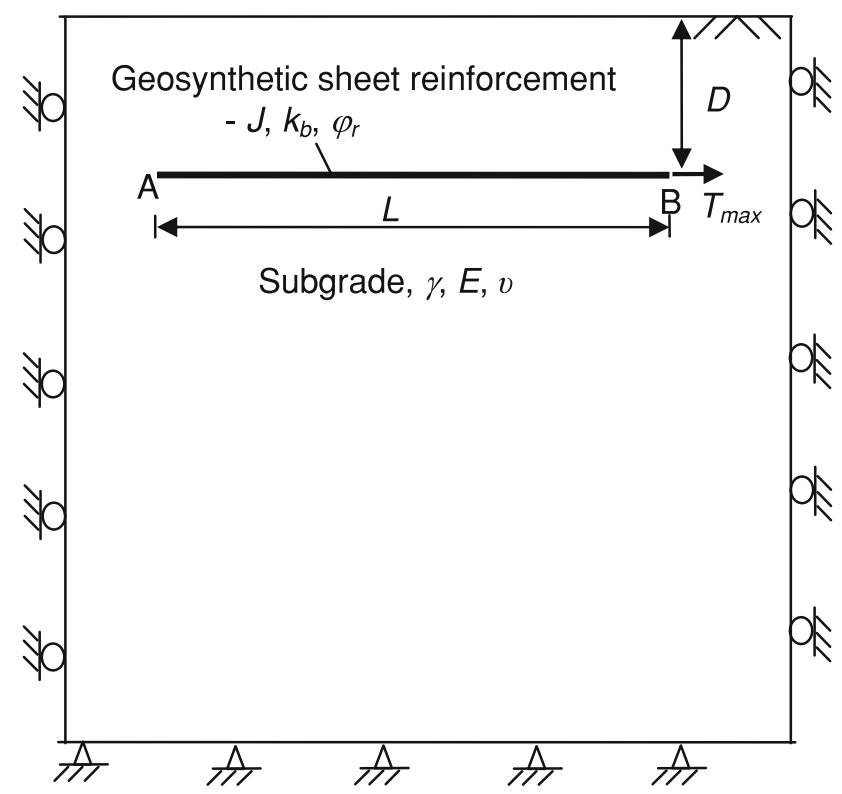

Fig. 1 Problem definition 


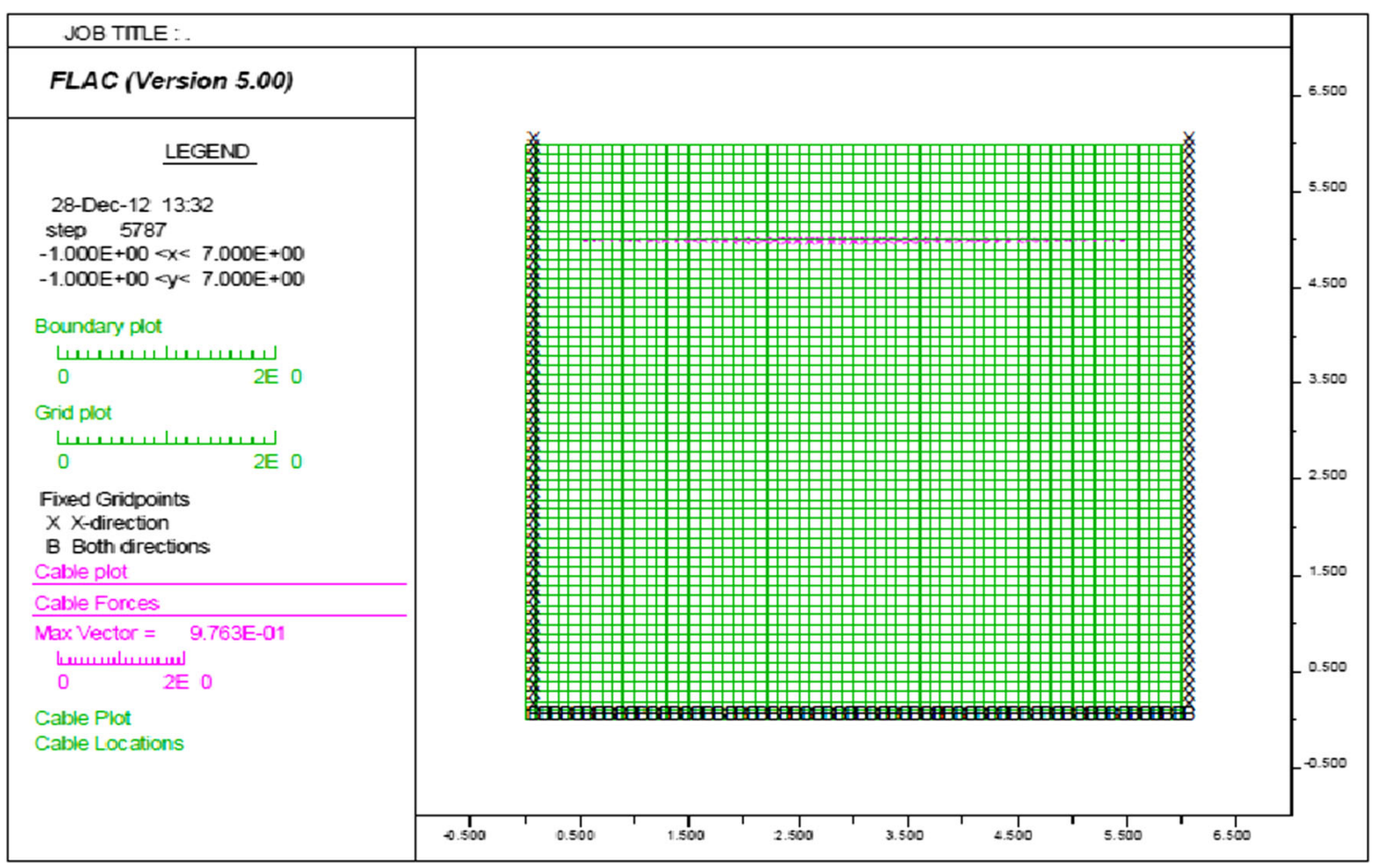

Fig. 2 Flac model

Fig. 3 Interface shear behavior of sheet elements a interface shear strength $\mathbf{b}$ shear force versus displacement [33] (a)



(b)

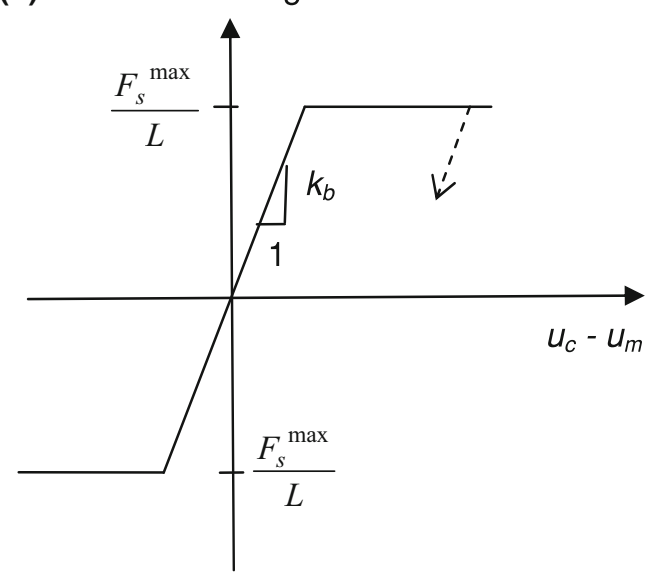

reinforcement; $\varphi_{\mathrm{r}}$ is the interface friction angle. Interface shear stress along the geosynthetic sheet depends on the relative displacement between the sheet and the soil interface (Fig. 3b, [33]). Shear stress along the interface is given by:

$\tau=\frac{F_{\mathrm{s}}}{L}=k_{\mathrm{b}}\left(u_{\mathrm{c}}-u_{\mathrm{m}}\right)$,

where $F_{\mathrm{s}}$ is the shear force along the reinforcement, $L$ is the length of sheet, $k_{\mathrm{b}}$ is the interface shear stiffness, $u_{\mathrm{c}}$ and $u_{\mathrm{m}}$ are the axial displacement of sheet and adjacent soil respectively. Shear stress-displacement relation in the present continuum model follows the initial slope of shear stress-displacement relation presented by Madhav et al. [30].

Geometric properties of sheet reinforcement such as cross sectional area and perimeter of the reinforcement are computed for $2 \mathrm{~mm}$ thick sheet for unit length perpendicular to the plane. Overburden pressure on sheet reinforcement is applied in the model by input of acceleration due to gravity of $10 \mathrm{~m} / \mathrm{sec}^{2}$. Model is rebuilt by several iterations and brought to equilibrium under the gravity stresses. Each grid point is surrounded by four material elements and the algebraic sum of the forces contributed by 
these surrounding elements at any specified grid point is defined as an unbalanced force. This unbalanced force should converge to zero when the model reaches equilibrium state. Other equilibrium criterion is stress ratio defined as maximum unbalanced force to the representative internal force. In the present work the equilibrium of the model is established based on the following criterianumber of iterations are restricted to one hundred thousand, the minimum stress ratio of 0.001 or the maximum unbalanced force of zero Newton. In most of the cases equilibrium state based on minimum stress ratio of 0.001 governs the solution.

Displacement of reinforcement, $w$ and tension $T$ at different nodes due to pullout force, $T_{\max }$ at node B is obtained from the numerical model and the obtained results are compared with mechanical model [30]. Large strain mode is adopted in the analysis to accurately predict the displacements and tensile forces at different nodes along the reinforcement.

\section{Results and Discussion}

Parametric study is carried for the following range of parameters: depth of reinforcement, $D=1-5 \mathrm{~m}$, length of reinforcement, $L=3-7 \mathrm{~m}$, shear stiffness of interface, $k_{\mathrm{b}}=25-200 \mathrm{kN} / \mathrm{m}^{3}$, axial stiffness of reinforcement, $J=0.1-5 \mathrm{MN} / \mathrm{m}$. Tensile yield strength of sheet reinforcement $=200 \mathrm{kN} / \mathrm{m}$ and interface friction angle, $\varphi_{\mathrm{r}}=30^{\circ}$.

Displacement profiles for different pullout forces, $T_{\max }$ at node B is presented in Fig. 4 for an axial stiffness of reinforcement, $J=1 \mathrm{MN} / \mathrm{m}$ and interface shear stiffness, $k_{\mathrm{b}}=100 \mathrm{kN} / \mathrm{m}^{3}$. Application of axial pullout force or horizontal displacement at node B develops shear stress at the soil reinforcement interface. This shear stress decreases towards free end of reinforcement depending on the

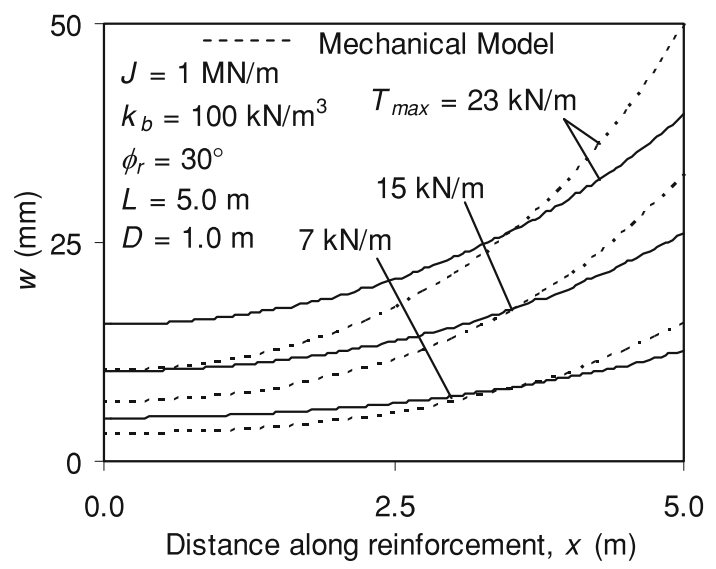

Fig. 4 Displacement profiles for different pullout loads at node B displacement of different nodes of reinforcement. Sheet reinforcement subjected to a pullout force, $T_{\max }$ of order $7 \mathrm{kN} / \mathrm{m}$ displaces the node B of reinforcement by $13 \mathrm{~mm}$ and free end of reinforcement by $5 \mathrm{~mm}$ (Fig. 4). Reinforcement slips by $5 \mathrm{~mm}$ and elongates by $8 \mathrm{~mm}$. Increase of pullout force, $T_{\max }$ by about three times to $23 \mathrm{kN} / \mathrm{m}$ results in a linear increase of displacement of node B by $40 \mathrm{~mm}$ and free end displacement by $16 \mathrm{~mm}$. Mechanical model based on discrete approach predicts an increase of displacement at node B and a subsequent decrease of displacement at free end of reinforcement for the same order of pullout force, $T_{\max }$ in comparison with continuum model. Tension profiles for different pullout forces, $T_{\max }$ is presented in Fig. 5.

Node B of sheet reinforcement with an axial stiffness, $J=1 \mathrm{MN} / \mathrm{m}$ is subjected to a pullout force, $T_{\max }=24 \mathrm{kN} / \mathrm{m}$ and interface shear stiffness, $k_{\mathrm{b}}$ is varied from 25 to $200 \mathrm{kN} / \mathrm{m}^{3}$. Corresponding tension and displacement profiles are presented in Figs. 6 and 7 respectively. Tension profiles for different interface shear stiffnesses, $k_{\mathrm{b}}$ are close to each other and are nearly independent of shear stiffness (Fig. 6). Increase of interface shear stiffness, $k_{\mathrm{b}}$ increases the shear stress acting on the reinforcement. An axial pullout force, $T_{\max }=24 \mathrm{kN} / \mathrm{m}$ displaces the end B of sheet reinforcement by $113 \mathrm{~mm}$ and free end of reinforcement by $85 \mathrm{~mm}$ for shear stiffness, $k_{\mathrm{b}}=25 \mathrm{kN} / \mathrm{m}^{3}$ while the node B displaces marginally by $27 \mathrm{~mm}$ and the free end of reinforcement by $6 \mathrm{~mm}$ for a higher interface shear stiffness, $k_{\mathrm{b}}=200 \mathrm{kN} / \mathrm{m}^{3}$ (Fig. 7). Displacement at node B and slip of reinforcement decreases drastically with increase of shear stiffness, $k_{\mathrm{b}}$ from 25 to $200 \mathrm{kN} / \mathrm{m}^{3}$ while the elongation of reinforcement decreases marginally from 28 to $21 \mathrm{~mm}$.

Displacement at node B increases linearly with increase of pullout force, $T_{\max }$ for interface shear stiffness, $k_{\mathrm{b}}$ ranging from 25 to $200 \mathrm{kN} / \mathrm{m}^{3}$ (Fig. 8). Pullout force, $T_{\max }$

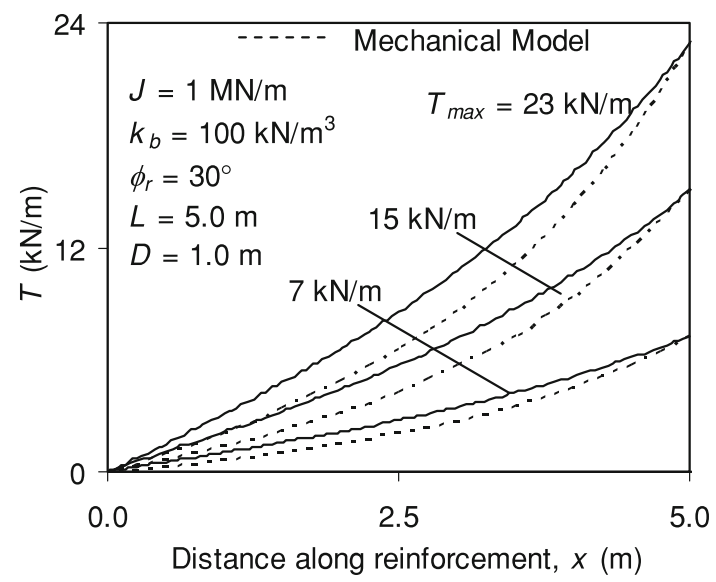

Fig. 5 Tension profiles for different pullout loads at node B 
necessary for a displacement of $50 \mathrm{~mm}$ at node $\mathrm{B}$ of reinforcement increases from 11 to $44 \mathrm{kN} / \mathrm{m}$ with increase of shear stiffness, $k_{\mathrm{b}}$ from 25 to $200 \mathrm{kN} / \mathrm{m}^{3}$. Mechanical model predicts a linear increase of pullout force, $T_{\max }$ for

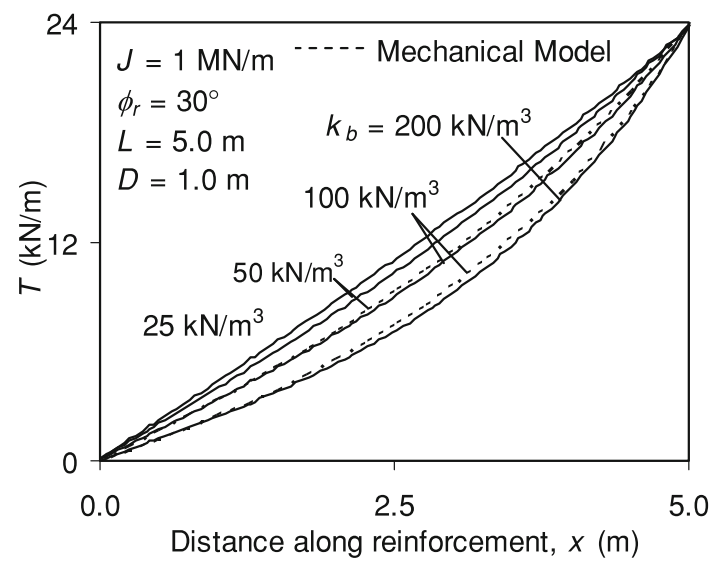

Fig. 6 Effect of interface shear stiffness on tension profiles

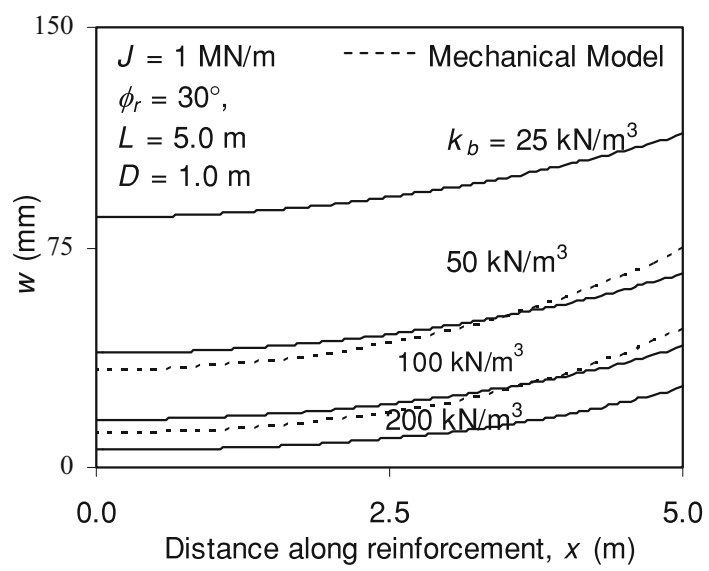

Fig. 7 Effect of interface shear stiffness on displacement profiles

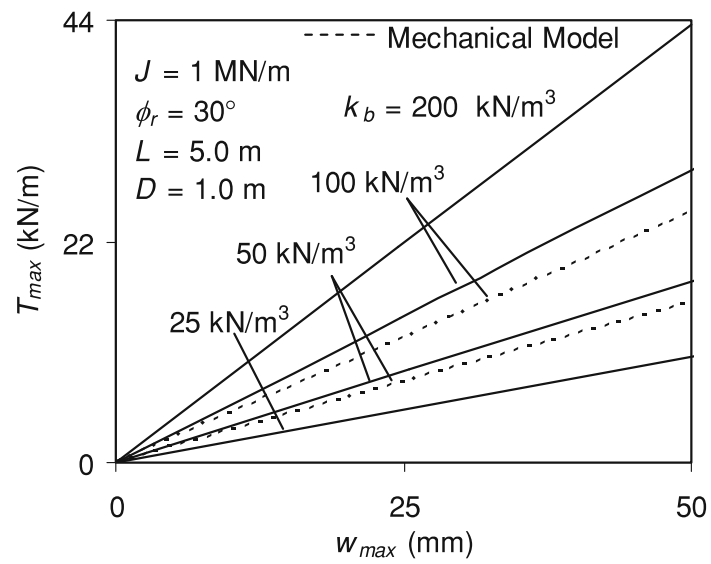

Fig. 8 Variation of maximum tension in reinforcement with horizontal displacement at node B-effect of shear stiffness different displacements of reinforcement, $w_{\max }$ at node B and shear stiffness, $k_{\mathrm{b}}$. Discrete approach results in slightly larger displacement for the same order of pullout force, $T_{\max }$ for a shear stiffnesses, $k_{\mathrm{b}}=50$ and $100 \mathrm{kN} / \mathrm{m}^{3}$ presented in Fig. 8.

Influence of axial stiffness of reinforcement, $J$ varying from 0.1 to $5 \mathrm{MN} / \mathrm{m}$ is presented for a constant shear stiffness, $k_{\mathrm{b}}=100 \mathrm{kN} / \mathrm{m}^{3}$. Tension developed in a relatively inextensible reinforcement with an axial stiffness, $J=5 \mathrm{MN} / \mathrm{m}$ increases linearly along the reinforcement length (Fig. 9). In a relatively extensible reinforcement of axial stiffness, $J=0.1 \mathrm{MN} / \mathrm{m}$ the pullout force, $\mathrm{T}_{\max }=$ $23 \mathrm{kN} / \mathrm{m}$ acting at node B decreases drastically to $8 \mathrm{kN} / \mathrm{m}$ at a distance of $1.0 \mathrm{~m}$ from node $\mathrm{B}$ and tension decreases gradually in the remaining length of reinforcement.

Pullout force, $T_{\max }=23 \mathrm{kN} / \mathrm{m}$ acting at node B of reinforcement with an axial stiffness $J=0.1 \mathrm{MN} / \mathrm{m}$ results in a displacement, $w$ of $114 \mathrm{~mm}$ at node B and displacement at middle and free end of reinforcement are 10 and $2 \mathrm{~mm}$ respectively (Fig. 10). Reinforcement elongates by $104 \mathrm{~mm}$ in half the length of reinforcement subjected to pullout force and the elongation in other half of the reinforcement is negligible. This behavior of extensible reinforcement changes gradually with increase of axial stiffness of reinforcement, $J$, from 0.1 to $5 \mathrm{MN} / \mathrm{m}$. Application of pullout force, $T_{\max }=23 \mathrm{kN} / \mathrm{m}$ at node B results in a displacement of $27 \mathrm{~mm}$ at node $\mathrm{B}$ and the displacement of free end of reinforcement is $21.5 \mathrm{~mm}$ for an axial stiffness of reinforcement, $J=5 \mathrm{MN} / \mathrm{m}$. A relatively inextensible reinforcement of stiffness, $J=5 \mathrm{MN} / \mathrm{m}$ results in a slip of reinforcement by $21.5 \mathrm{~mm}$ and elongation of $5.5 \mathrm{~mm}$. Mechanical model predicts an increase of displacement at node B and subsequent decrease of displacement at free end of reinforcement for the same pullout force at node $\mathrm{B}$ for a stiffness of reinforcement, $J=0.25 \mathrm{MN} / \mathrm{m}$.

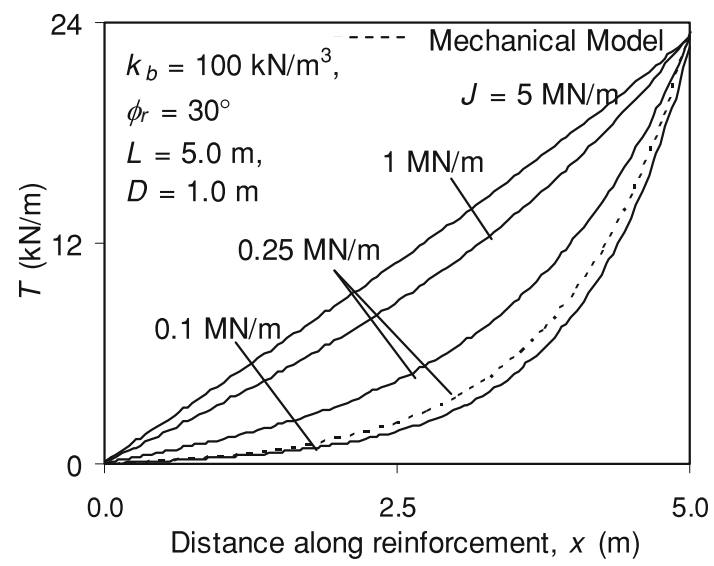

Fig. 9 Effect of axial stiffness of reinforcement on tension profiles 


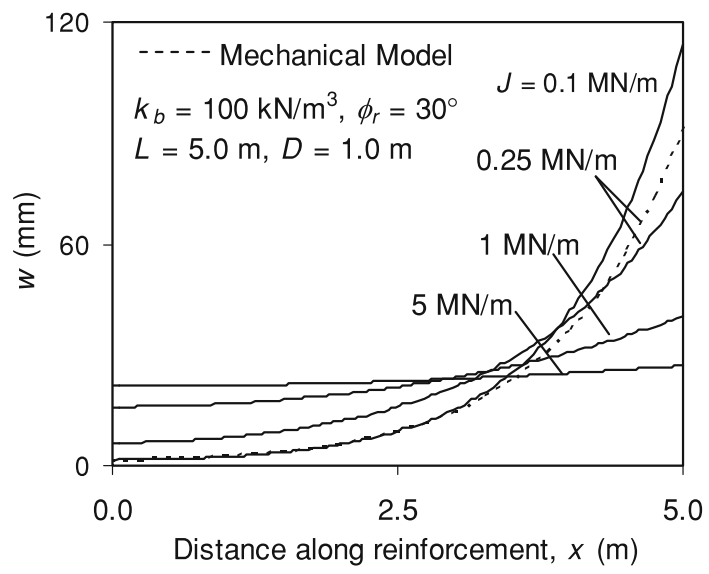

Fig. 10 Effect of axial stiffness of reinforcement on displacement profiles

Displacement of reinforcement increases linearly with increase of pullout force, $T_{\max }$ at node $\mathrm{B}$ for the axial stiffness of reinforcement, $J$ ranging from 0.1 to $5 \mathrm{MN} / \mathrm{m}$ (Fig. 11). Pullout force, $T_{\max }$ necessary for a displacement of $50 \mathrm{~mm}$ at node B increases from 10 to $44 \mathrm{kN} / \mathrm{m}$ with increase of axial stiffness of reinforcement, $J$ from 0.1 to $5 \mathrm{MN} / \mathrm{m}$. Mechanical model predicts a slightly larger displacement for the pullout force, $T_{\max }$ of same order at node B for an axial stiffness of reinforcement, $J=0.25 \mathrm{MN} / \mathrm{m}$ in comparison with that based on the continuum model.

Length of reinforcement on either side of the failure plane or surface varies with depth below the top of reinforced soil structure. Effect of axial pullout on the length of reinforcement, $L$, varied from 3.0 to $7.0 \mathrm{~m}$ for an interface shear stiffness, $k_{\mathrm{b}}=100 \mathrm{kN} / \mathrm{m}^{3}$ and axial stiffness, $J=1 \mathrm{MN} / \mathrm{m}$ is presented in Fig. 12. Tension profile is almost linear for smaller length of reinforcement, $L=3.0 \mathrm{~m}$. Increase of length of reinforcement, $L$ to $7.0 \mathrm{~m}$

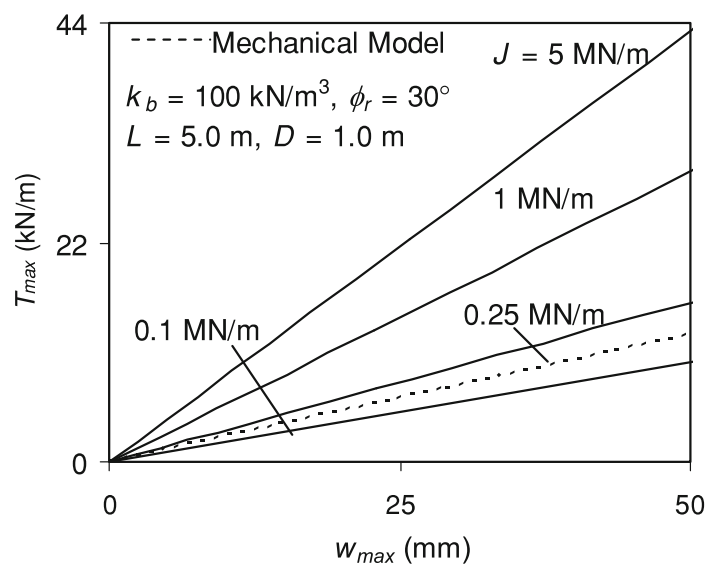

Fig. 11 Variation of maximum tension in reinforcement with horizontal displacement at end B-effect of axial stiffness of reinforcement

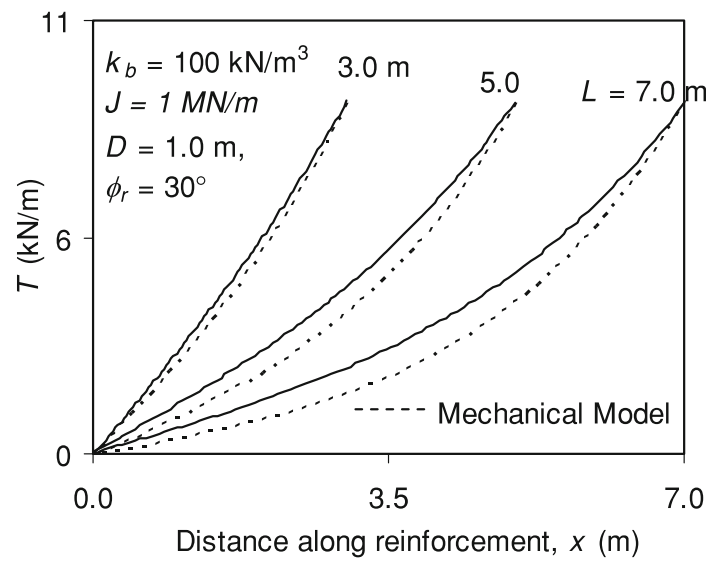

Fig. 12 Effect of length of reinforcement on tension profiles

results in a gradual decrease of slope of tension profile towards free end of reinforcement.

Pullout force, $T_{\max }$ of $9 \mathrm{kN} / \mathrm{m}$ at node B results in a displacement of $19 \mathrm{~mm}$ at node $\mathrm{B}$ and a free end displacement of $13 \mathrm{~mm}$ resembling rigid body displacement for a shorter length of reinforcement, $L=3.0 \mathrm{~m}$ (Fig. 13). Reinforcement elongates by $6 \mathrm{~mm}$ and slips by $13 \mathrm{~mm}$ for a shorter length of reinforcement, $L=3.0 \mathrm{~m}$. Pullout force of $9 \mathrm{kN} / \mathrm{m}$ at node B on a longer length of reinforcement, $L=7.0 \mathrm{~m}$ displaces node B of reinforcement by $15 \mathrm{~mm}$ and the free end of reinforcement by $3 \mathrm{~mm}$. Reinforcement elongates by $12 \mathrm{~mm}$ and slips marginally by $3 \mathrm{~mm}$ for a longer length of reinforcement, $L=7 \mathrm{~m}$. Elongation of reinforcement occurs over half of the length of reinforcement subjected to pullout load and the elongation of other half of the reinforcement is negligible for longer length of reinforcement. For the same order of pullout load shorter length of reinforcement results in slip or rigid body displacement while longer reinforcement elongates. Displacement and tension profiles presented by mechanical model compare closely with the results of numerical model

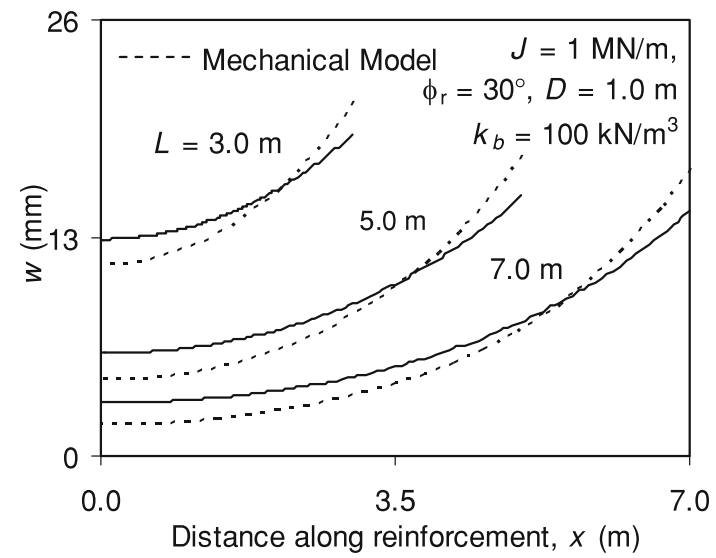

Fig. 13 Effect of length of reinforcement on displacement profiles 
for different lengths of reinforcement, $L$ ranging from 3.0 to $7.0 \mathrm{~m}$.

Displacement of reinforcement increases linearly with increase of pullout force at node B for different lengths of reinforcement, $L$ ranging from 3.0 to $7.0 \mathrm{~m}$ (Fig. 14). Pullout force, $T_{\max }$ at node B is 42,53 and $56 \mathrm{kN} / \mathrm{m}$ for a displacement of $90 \mathrm{~mm}$ at node $\mathrm{B}$ for the length of reinforcement, $L=3.0,5.0$ and $7.0 \mathrm{~m}$ respectively.

Comparison of Results with Other Analytical and Field Test Results

Konami et al. [34] analyzed geosynthetic reinforcement subjected to axial pullout force by assuming full shear stress mobilization along the reinforcement soil interface. Elongation of reinforcement at the loaded end is quantified by considering the equilibrium of pullout force, tension developed in the reinforcement and full shear resistance acting on the reinforcement soil interface. Elongation due to pullout force, $D_{0}$ is expressed as

$D_{0}=\frac{T_{\mathrm{pu}}^{2}}{4 E t \mu \sigma_{\mathrm{n}}}$,

where $T_{\mathrm{pu}}$ is the pullout force, Et is the stiffness of the reinforcement, $\mu$ is the friction coefficient and $\sigma_{\mathrm{n}}$ is the normal stress acting on the reinforcement.

Konami et al. [34] conducted field pullout tests on polymer strip reinforced soil wall. Three types of polymeric strip reinforcements, named PW-3, PW-5 and PW-10 were used in the field pullout tests. These strips were made of fiber coated with polyethylene of $8.5,9.0$ and $9.0 \mathrm{~cm}$ wide respectively. Thickness of the strips was 2,3 and $5 \mathrm{~mm}$ respectively. Details of secant rigidity at 2 and $5 \%$ strains, nominal strength and elongation due to tension failure are mentioned in the paper by Konami et al. [34].

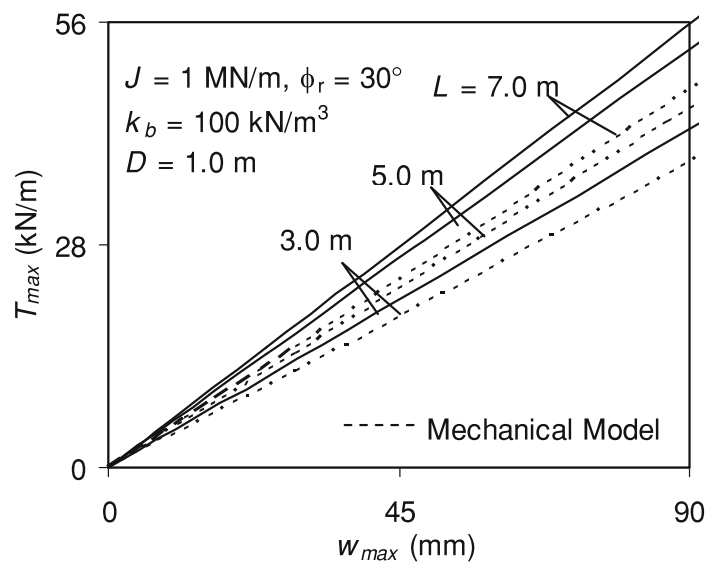

Fig. 14 Variation of maximum tension with horizontal displacement at end $\mathrm{B}$ - effect of length of reinforcement
Height of reinforced test wall was $6.4 \mathrm{~m}$ and crest length was $12 \mathrm{~m}$. Reinforcement layout and pullout test numbers $1-8$ are mentioned in the cross section of the reinforced soil wall presented in Fig. 15. Lengths of reinforcement were 3.5 and $5.5 \mathrm{~m}$ and spacing between the strip reinforcement layers was uniform and equal to $0.8 \mathrm{~m}$. Pullout force is applied at a rate of $1 \mathrm{~cm} / \mathrm{min}$ on strip reinforcement. Displacements of loaded end with pullout force in different tests are presented in Figs. 16, 17, 18, 19, 20 and 21. Elongation of the reinforcement for different pullout loads are predicted by Eq. 3 and presented in Figs. 16, 17, 18, 19, 20 and 21.

Madhav et al. [30] estimated the interface shear stiffness, $k_{\mathrm{b}}$ for different pullout tests to plot the best fit of field pullout curves. Shear stiffness, $k_{\mathrm{b}}$, interface friction angle, $\varphi_{\mathrm{r}}$ and axial stiffness of reinforcement used in the study are presented in Table 1. Variation of displacement with pullout load for the above estimated pullout parameters is presented in Figs. 16, 17, 18, 19, 20 and 21.

Displacement of node B is quantified by FLAC for different pullout forces, $T_{\max }$ for the shear stiffness, $k_{\mathrm{b}}$, axial stiffness, $J$ and interface friction coefficient, $\mu$ mentioned in Table 1 . The variation of displacement at node B for different pullout loads is presented in Figs. 16, 17, 18, 19, 20 and 21.

Variation of displacement of reinforcement at node B for different pullout loads predicted by mechanical model compare closely with the experimental results in Figs. 16, 17, 18, 19, 20 and 21. Displacements quantified by the present numerical model are marginally less for the same

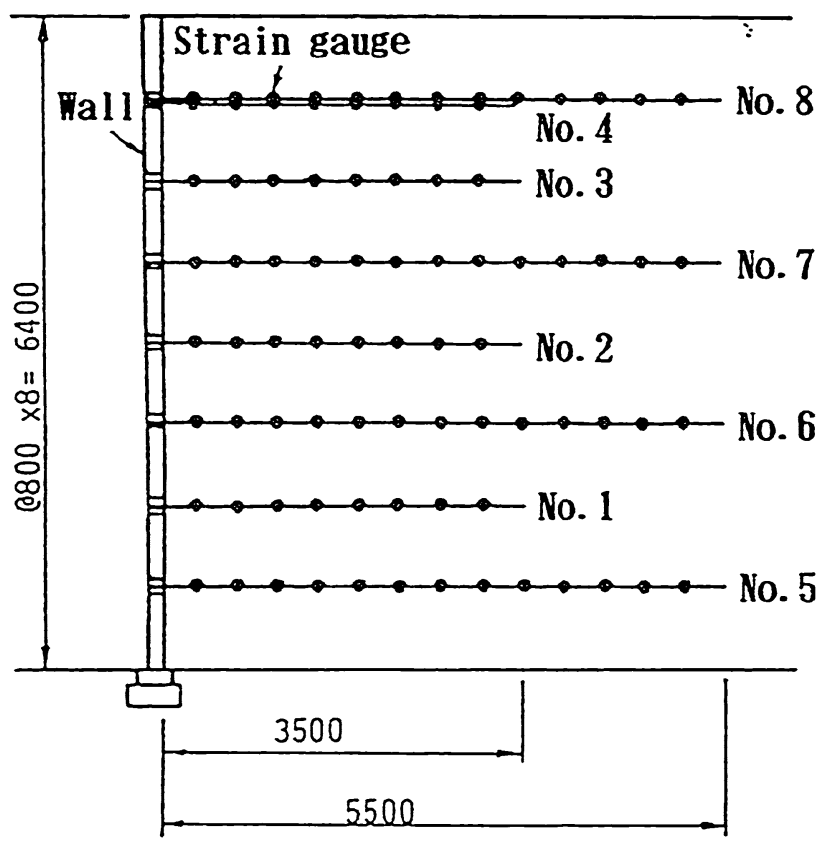

Fig. 15 Section of RS wall for field pullout test [34] 


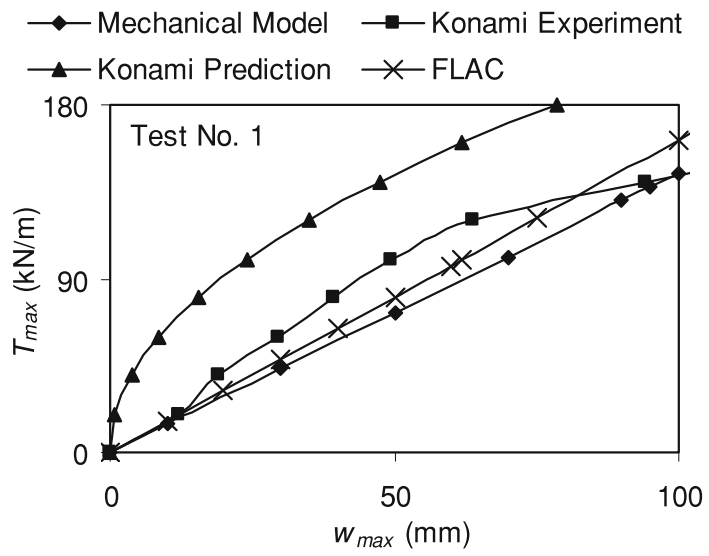

Fig. 16 Comparison of predicted results with field test No. 1 of Konami et al. [34]

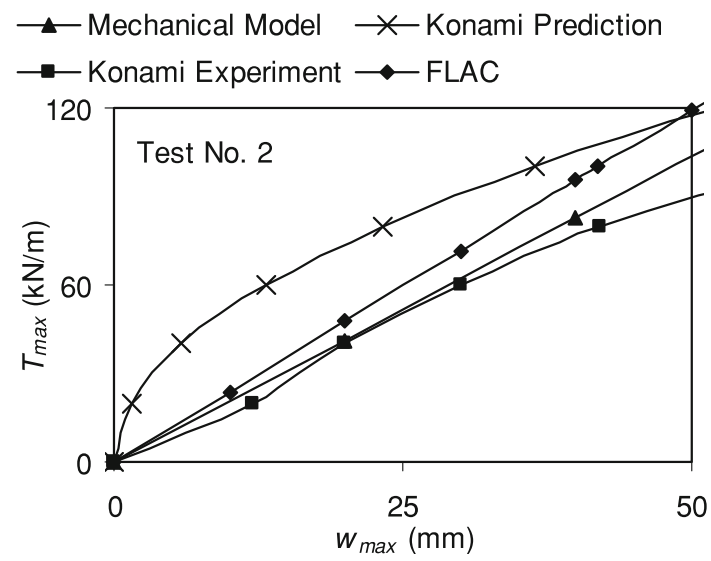

Fig. 17 Comparison of predicted results with field test No. 2 of Konami et al. [34]

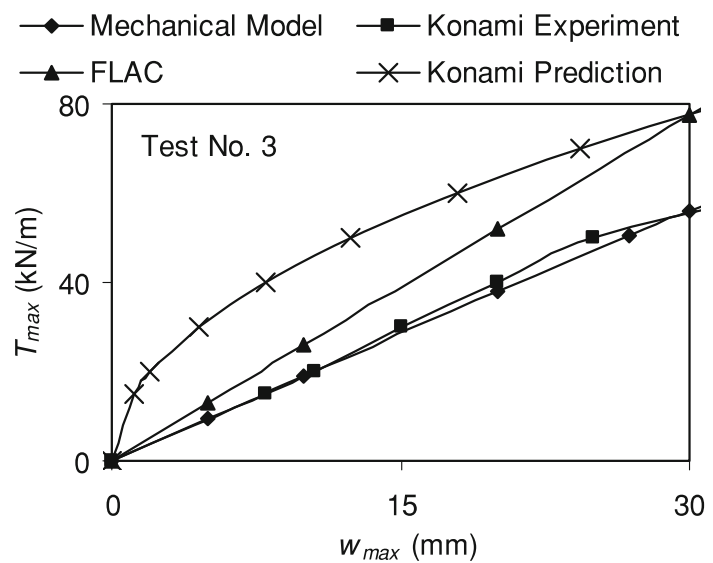

Fig. 18 Comparison of predicted results with field test No. 3 of Konami et al. [34]

order of pullout force when compared with the predictions of mechanical model. Variation of pullout load with displacement is linear based on the predictions of numerical

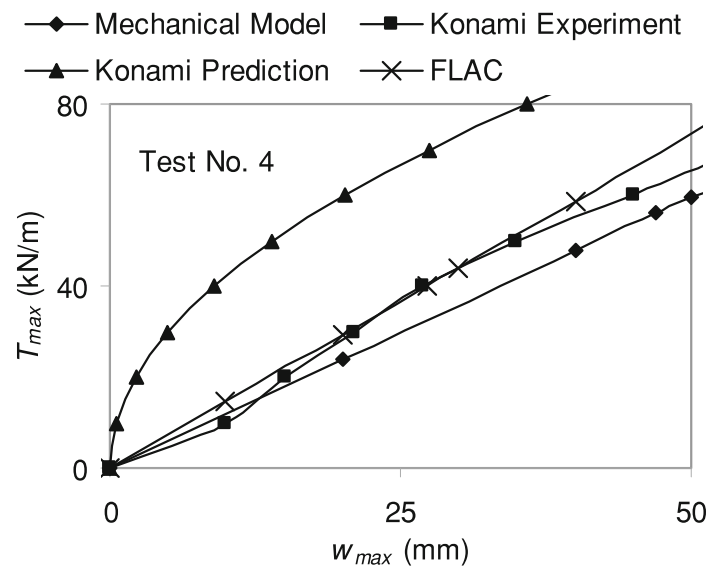

Fig. 19 Comparison of predicted results with field test No. 4 of Konami et al. [34]

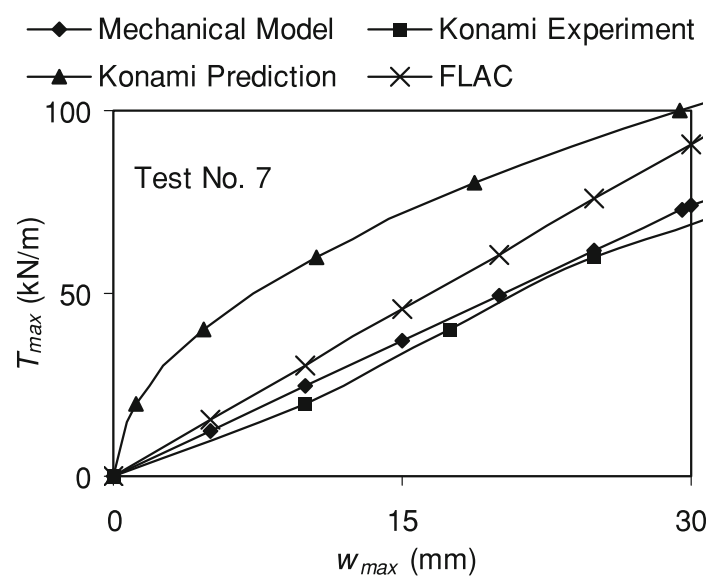

Fig. 20 Comparison of predicted results with field test No. 7 of Konami et al. [34]

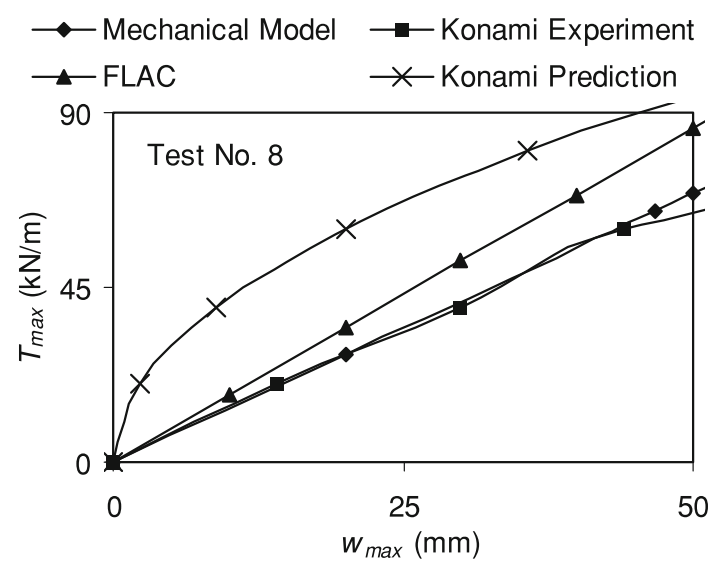

Fig. 21 Comparison of predicted results with field test No. 8 of Konami et al. [34]

model and these results are comparable with the experimental predictions for smaller displacement/pullout force. Konami et al. [34] underestimate the displacements 
Table 1 Estimated pullout test parameters for comparison with experimental results [30]

\begin{tabular}{llll}
\hline Test number & $\begin{array}{l}\text { Shear stiffness, } \\
k_{\mathrm{b}} \text { in } \mathrm{kN} / \mathrm{m}^{3}\end{array}$ & $\begin{array}{l}\text { Axial stiffness, } \\
J \text { MN/m }\end{array}$ & $\begin{array}{l}\text { Interface friction } \\
\text { coefficient, } \mu\end{array}$ \\
\hline 1 & 272.9 & 5.97 & 0.30 \\
2 & 443.5 & 5.97 & 0.44 \\
3 & 483.0 & 3.88 & 0.45 \\
4 & 245.5 & 3.88 & 0.80 \\
7 & 483.5 & 5.97 & 0.33 \\
8 & 246.9 & 3.88 & 0.80 \\
\hline
\end{tabular}

compared with the other results due to the assumption of full shear stress mobilization along the reinforcement-soil interface. Predictions of displacement of reinforcement for different axial pullout forces based on FLAC compare closely with other mechanical/theoretical and experimental results.

\section{Conclusions}

Response of polymeric sheet reinforcement subjected to axial force at its free end is studied using FLAC for a range of interface shear stiffnesses and axial stiffnesses of reinforcement and for different lengths of reinforcement.

- Results of the axial pullout of sheet reinforcement based on FLAC compare closely with the results of mechanical model given by Madhav et al. [30]. Marginal difference between the two methods is due to the continuum and discrete approaches adopted.

- Displacement of loaded end of reinforcement subjected to an axial pullout force of $24 \mathrm{kN} / \mathrm{m}$ increases from 27 to $113 \mathrm{~mm}$ with decrease of interface shear stiffness from 200 to $25 \mathrm{kN} / \mathrm{m}^{3}$ and elongation of reinforcement is nearly constant.

- Inextensible reinforcement $(J=5 \mathrm{MN} / \mathrm{m})$ subjected to an axial pullout force of $23 \mathrm{kN} / \mathrm{m}$ mobilizes a uniform shear stress and undergoes a rigid body displacement of about $25 \mathrm{~mm}$.

- Extensible reinforcement $(J=0.1 \mathrm{MN} / \mathrm{m})$ subjected to an axial pullout force of $23 \mathrm{kN} / \mathrm{m}$ undergoes a larger displacement of $114 \mathrm{~mm}$ at loaded end of reinforcement while the displacements of the free of end of reinforcement is negligible. Shear stress mobilized at loaded end of reinforcement is large while it is negligible at the free end.

- For the same order of axial pullout force, shorter length of reinforcement undergoes rigid body displacement and longer length of reinforcement elongates. Displacement at free end of reinforcement is small for longer length of reinforcement compared to that for shorter length of reinforcement.
- Pullout force to be applied for a given displacement increases with increase of interface shear stiffness, axial stiffness of reinforcement and marginally with length of reinforcement.

Predicted pullout force versus displacement relation is comparable with the results of mechanical model by Konami et al. [34], Madhav et al. [30] and the field pullout tests by Konami et al. [34].

\section{References}

1. Juran I, Chen CL (1988) Soil-geotextile pull-out interaction properties: testing and interpretation. Transp Res Rec 1188:37-47

2. Palmeria EM, Milligan GWE (1989) Scale and other factors affecting the results of pull-out tests of grids buried in sand. Geotechnique 39(3):511-524. doi:10.1680/geot.1989.39.3.511

3. Farrag K, Acar YB, Juran I (1993) Pull-out resistance of geogrid reinforcement. Geotext Geomembr 12(2):133-159. doi:10.1016/ 0266-1144(93)90003-7

4. Fannin RJ, Raju DM (1993) On the pullout resistance of geosynthetics. Can Geotech J 30(3):409-417

5. Kutara K, Aoyama H, Yayunaga H, Kato T (1988) Long-term pullout tests of polymer grid in sand. In: Proceedings of the international geotechnical symposium on theory and practice of earth reinforcement, Balkema

6. Yasuda S, Nagase H, Marui H (1992) Cyclic pullout tests of geogrids in soils. Proc Int Symp Earth Reinf Pract, Fukuoka

7. Hanna TH, Touhamia M (1991) Comparative behavior of metal and tensar geogrid strips under static and repeated loading. In: Proceedings of the geosynthetics'91 conference, IFAI, Atlanta

8. Aiban SA, Ali SM (2001) Nonwoven geotextile-sabkha and -sand interface friction characteristics using pullout tests. Geosynth Int 8(3):193-220. doi:10.1680/gein.8.0192

9. Khedkar MS, Mandal JN (2009) Pullout behaviour of cellular reinforcements. Geotext Geomembr 27(4):262-271. doi:10.1016/ j.geotexmem.2008.12.003

10. Suksiripattanapong C, Chinkulkijniwat A, Horpibulsuk S, Rujikiatkamjorn C, Tanhsutthinon T (2012) Numerical analysis of bearing reinforcement earth (BRE) wall. Geotext Geomembr 32(1):28-37. doi:10.1016/j.geotexmem.2012.01.002

11. Suksiripattanapong C, Horpibulsuk S, Chinkulkijniwat A, Chai JC (2013) Pullout resistance of bearing reinforcement embedded in coarse-grained soils. Geotext Geomembr 36(1):44-54. doi:10. 1016/j.geotexmem.2012.10.008

12. Lajevardi SH, Dias D, Racinais J (2013) Analysis of soil-welded steel mesh reinforcement interface interaction by pull-out tests. 
Geotext Geomembr 40(1):48-57. doi:10.1016/j.geotexmem. 2013.08.002

13. NF P 94-270 (2009) French design standard, Calcul géotechnique-Ouvrages de soutènement-Remblais renforcés et massifs en sol cloué

14. Jewell RA (1990) Reinforcement bond capacity. Geotechnique 40(3):513-518. doi:10.1680/geot.1990.40.3.513

15. Abramento M, Whittle AJ (1993) Shear lag-analysis of a planar soil reinforcement in plane strain compression. J Eng Mech ASCE 119(2):270-291. doi:10.1061/(ASCE)0733-9399(1993) 119:2(270)

16. Abramento M, Whittle AJ (1995) Experimental evaluation of pullout analyses for planar reinforcements. J Geotech Eng 121(6):486-492. doi:10.1061/(ASCE)0733-9410(1995)121:6(486)

17. Hayashi S, Makiuchi K, Ochiai H (1994) Testing methods for soil-geosynthetic frictional behavior-Japanese standard. In: Proceedings of the 5th international conference on geotextiles, geomembranes and related products, Singapore

18. Pradhan TBS, Shiwakoti DR, Imai G (1996) Effect of normal pressure and width of geosynthetic horizontal drain in pullout behaviour using saturated clay. Proc Int Symp Earth Reinf, Japan

19. Sobhi S, Wu JTH (1996) Interface pullout formula for extensible sheet reinforcement. Geosynth Int 3(5):565-581. doi:10.1680/ gein.3.0075

20. Long PV, Bergado DT, Balasubramanian AS (1997) Interaction between soil and geotextile reinforcement. ASCE Geotech Spec Publ 69:560-578

21. Weerasekara L, Wijewickreme D (2010) An analytical method to predict the pullout response of geotextiles. Geosynth Int 17(4):193-206. doi:10.1680/gein.2010.17.4.193

22. Koerner RM, Wayne MH, Carroll RG (1989) Analytic behavior of geogrid anchorage. In: Proceedings international geosynthetics'89 Conference, IFAI, San Diego

23. Peterson LM, Anderson LR (1980) Pullout resistance of welded wire mats embedded in soil. Research Report submitted to Hilfiker Company, Utah State University, Eureka
24. Jewell RA, Paine N, Woods RI (1984) Design methods for steep reinforced embankments. In: Proceedings of symposium on polymer grid reinforcement in civil engineering, London

25. Chai JC (1992) Interaction between grid reinforcement and cohesive-frictional soil and performance of reinforced wall/embankment on soft ground. D. Eng. Dissertation, Asian Institute of Technology

26. Teixeira SHC, Bueno BS, Zornberg JG (2007) Pullout resistance of individual longitudinal and transverse geogrid ribs. J Geotech Geoenviron Eng 133(1):37-50. doi:10.1061/(ASCE)-0241(2007) 133:1(37)

27. Sugimoto M, Alagiyawanna A (2003) Pullout behavior of geogrid by test and numerical analysis. J Geotech Geoenviron Eng ASCE 129(4):361-371. doi:10.1061/(ASCE)1090-0241(2003)129:4(361)

28. Alam M, Lo S (2013) Numerical modeling of the pull-out test of steel grid soil reinforcement using FLAC2D. Geo-Congress 2013:10-18. doi:10.1061/9780784412787.002

29. Alam M, Lo SR, Karim MR (2014) Pull-out behaviour of steel grid soil reinforcement embedded in silty sand. Comput Geotech 56(1):216-226. doi:10.1016/j.compgeo.2013.12.004

30. Madhav MR, Gurung N, Iwao Y (1998) A theoretical model for the pull-out response of geosynthetic reinforcement. Geosynth Int 5(4):399-424. doi:10.1680/gein.5.0128

31. Gurung N, Iwao Y (1999) Comparative model study of geosynthetic pull-out response. Geosynth Int 6(1):53-68. doi:10.1680/ gein.6.0143

32. Gurung N (2001) 1-D analytical solution for extensible and inextensible soil/rock reinforcement in pull-out tests. Geotext Geomembr 19(4):195-212. doi:10.1016/S0266-1144(01)00008-5

33. Fast Lagrangian Analysis of Continua User guide Version 6.0 (2008) 4th edn, p 1.73-1.91

34. Konami T, Imaizumi S, Takahashi S (1996) Elastic considerations of field pull-out tests of polymer strip reinforcement. In: Proceedings of the international symposium on earth reinforcement, Fukuoka 